Manuscript ID

ZUMJ-1906-1246 (R6)

DOI

10.21608/zumj.2019.13437.1246

ORIGINAL ARTICLE

\title{
Frequency Of Otitis Media with Effusion Among Preschool Children and Its Effect On Both Children And Their Parents: A Cross-sectional Study
}

\author{
Khaled Abd EL-Shakor Mohammed ${ }^{1}$, Amany Mohammed Abdallah², Mona Ahmed Mohammed \\ EL-Didamony ${ }^{3} *$ \\ ${ }^{1}$ ENT Department, Faculty of Medicine, Zagazig University, Sharkia Egypt. \\ ${ }^{2}$ Family Medicine Department, Faculty of Medicine, Zagazig University, Sharkia Egypt. \\ ${ }^{3}$ Resident of Family Medicine, South Sinai, Ministry of health, Egypt.
}

*Corresponding Author:
Mona Ahmed Mohammed
EL-Didamony
Phone : (+20) 1003632357
Email:
dr_ahmed_hassanin2009@y
$\underline{\text { ahoo.com }}$
Submit Date 2019-06-10
Revise Date 2019-08-02
Accept Date 2019-08-04

*Corresponding Author:

ohammed

Phone : (+20) 1003632357

Email:

dr_ahmed_hassanin2009@y

\begin{abstract}
Background and aim:The impact of otitis media with effusion (OME) on quality of life (QoL) may be substantial. The aim of this study is to determine the magnitude of OME among children and its determinate effects on both them and their parents.

Method:A cross-sectional study was conducted on 98 apparently healthy preschool children attending the otolaryngology clinic at Zagazig University hospital. The studied children underwent socioeconomic data assessment and clinical examination. Diagnosis of OME was established using otoscope and tympanometry. QoL in children and also level of parents stress were measured.

Results: Mean age of the studied children was $3.27 \pm 1.53$ years. Of them, 22 $(22.4 \%)$ had OME. There is a statistically significant difference between presence of OME and crowding index, mother education, parent smoking and type of feeding. Regression analysis showed that only four factors were found significant in this analysis: crowding index $>2$ /room (odds ratio $(\mathrm{OR})=9.36$ ), parent smoking in the household $(\mathrm{OR}=3.72)$, mother education less than secondary school education $(\mathrm{OR}=9.02)$ and recurrent acute otitis media $(\mathrm{AOM})$ $(\mathrm{OR}=7.27)$. There is a significant difference between the studied children with and without OME regarding emotional functioning, school performance, and total QoL domains. There is a significant difference between the studied children regarding parents' stressConclusion:

Having recurrent AOM, parent smoking in the household were strong predictors of the occurrence of OME. Children with OME reported significantly poorer quality of life and their parents had higher perceived stress.

Keywords: Otitis media; Children; Quality of life
\end{abstract}

\section{INTRODUCTION}

The definition of otitis media and its consequences has changed over the years. Otitis media with effusion (OME) is an accumulation of fluid in the middle ear in the absence of signs of acute inflammation. It is the most common cause of acquired hearing loss in childhood. It has a bimodal age distribution. it is common in children between the ages of one to three years, especially in the winter season. ${ }^{1}$ Otitis media with effusion is common in more than two-thirds of young children because their Eustachian tube (ET) anatomy and function do not provide adequate ventilation and drainage of natural mucus during a cold. Even with the widespread use of pneumococcal conjugate vaccines, acute otitis media (AOM) following 
an upper respiratory tract infection (URTI) remains common in childhood. ${ }^{2}$

The cumulative incidence to the age of four years is $80 \%$, and at age seven, the prevalence is still $3 \%$ to $8 \%$. $^{3}$ Otitis media with effusion may be associated with otalgia, infection and/or hearing loss. Hearing loss may be significant $(20 \mathrm{~dB}$ to $30 \mathrm{~dB})$, specifically when it is bilateral and has lasted for more than a month. ${ }^{4}$ However, some children have nearly normal hearing despite the presence of fluid within the middle ear. The hearing loss and discomfort may have linguistic, developmental, behavioral, and other social consequences, especially if the effusion is bilateral and of long duration. Otitis media is related to difficulties in speech, delayed response to auditory input, and disturbances in attention. It may also be associated with less task oriented and less capable of independent colleagues.

Observational studies measuring caregiver reports showed that school performance might improve after OME has been identified and treated. ${ }^{6}$ The impact of OME on diseasespecific quality of life (QOL) and functional health status may be substantial, affecting children and caregivers.

According to the parental report, $76 \%$ of children with OME suffer from otalgia, 49\% from behavioral problems, $64 \%$ from sleep disruption, $35 \%$ to $62 \%$ from speech and hearing concerns, and $15 \%$ from balance symptoms. Also, child and parent interaction may be poorer than in healthy children, and caregiver concerns are high. OME has an impact on child QOL. OME may result in sequelae that include tympanic membrane atelectasis, cholesteatoma formation, ossicular erosion, and tympanic membrane perforation. ${ }^{7}$

Due to the lake of data about the effects of otitis media with effusion on preschool children and their parents, the objective of this study was to determine the magnitude and risk factors of otitis media with effusion among preschool children attending Zagazig university otolaryngology clinic and its determinate effects on their quality of life and their parents

\section{PATIENT AND METHODS}

We followed Strengthening the Reporting of Observational Studies in Epidemiology (STROBE) statement guidelines when reporting this manuscript. The present study was approved by the ethical committee of Zagazig University, through the period of September 2018 to February 2019. Written informed consent was obtained from all participants' patients. The work has been carried out in accordance with The Code of Ethics of the World Medical Association (Declaration of Helsinki) for studies involving humans.

\subsection{Study Design, Study Setting, and Study} Participants

We conducted an epidemiological crosssectional study in the otolaryngology clinic at Zagazig University. The children were selected via systematic random sampling technique. We included apparently healthy children with less than six years old. Exclusion criteria were; children above six years old, children with chronic health problems, and patients who refused to participate in this study. The children will be selected by simple random technique. Every third child attending the audiology unit was included in the study.

\subsection{Sample size}

Sample size calculation was measured using Epi info-7 to be 98 cases with confidence level $95 \%$ and power of $80 \%$ after assuming that the prevalence of otitis media with effusion in Egypt is $16 \%$. We used a systematic random method to select the patients.

\subsection{Diagnostic criteria and tools of $\mathrm{OME}$}

In the diagnosis of OME, pneumatic otoscopy remains to be the gold standard. The use of other diagnostic tools in addition to pneumatic otoscopy, such as impedance audiometry and tympanocentesis, further improve the diagnostic accuracy.

\subsection{Study Assessments and Data Collection}

For each eligible patient, we reported the following data:

\section{a) Socio-demographic information of the study:}

A structured questionnaire was developed to collect socio-demographic information of the 
study participants (age, sex, residence, education, etc.)

\section{b) Pediatric Quality Of Life Inventory (Peds $Q L)$ :}

Health-related quality of life in children under trial using Pediatric Quality Of Life Inventory version 4 (Peds QL-4). Peds QL is a modular instrument for measuring health-related quality of life in children and adolescents ages 2 to 18 . The Peds QL 4.0 generic core scales are multidimensional child self-report as the generic core measure to be integrated with the Peds QL disease-specific modules. The Peds QL 4.0 generic core scales which consist of 23 items. The 4 Peds QL 4.0 generic core scales are; Physical Functioning (8 items), Social Functioning (5 items), Emotional Functioning (5 items), and School functioning (5 items), The following scores were used: 0 if it is never a problem, 1 if it is almost a problem, 2 if it is sometimes a problem, 3 if it is often a problem, and 4 if it is almost always a problem. If the if the parents were illiterate, we read the questions to the parents ${ }^{8}$.

\section{c) Perceived stress scale}

The questionnaire forms included personal and familial items. The Perceived Stress Scale (PSS) is a classic stress assessment instrument. The tool remains a popular choice for helping us understand how different situations affect our feelings and our perceived stress. The questions in this scale ask about your feelings and thoughts during the last month. In each case, you will be asked to indicate how often you felt or thought a certain way. Although some of the questions are similar, there are differences between them and you should treat each one as a separate question. For each question choose from the following alternatives: 0 - never, 1 - almost never, 2 sometimes, 3 - fairly often, and 4 - very often. We determined the PSS score by following these directions: First, reverse the scores for questions $4,5,7$, and 8 . On these 4 questions, change the scores like this: $0=4,1=3,2=2,3$ $=1,4=0$. Individual scores on the PSS can range from 0 to 40 with higher scores indicating higher perceived stress. Scores ranging from 0-
13 would be considered low stress. Scores ranging from 14-26 would be considered moderate stress. Scores ranging from 27-40 would be considered high perceived stress. ${ }^{9}$

\subsection{Pilot study}

A pilot study was carried out on $10 \%$ of the sample attending Zagazig university otolaryngology clinic to test the validity of the used questionnaire. It also helped to estimate the time needed for data collection. The patients included in the pilot study were excluded from the main sample.

\subsection{Study Process.}

All subjects included in this study were interviewed, and their parents were asked each of them. The parents were asked to fill in the PedsQL questionnaire. Time taken to fill the questionnaire was about 15 minutes. In addition, each child underwent complete ENT evaluation with an assessment of OME by otoscopeby the ENT specialist.

\subsection{Statistical Analysis}

All data were analyzed using SPSS 25.0 for Windows (SPSS Inc., Chicago, Illinois, USA). MedCalc Statistical Software version 14.8.1 (MedCalc Software bvba, Ostend, Belgium; http://www.medcalc.org; 2014). Continuous variables were expressed as mean $\pm \mathrm{SD}$, median and range while the categorical variables were expressed as a number (percentage). Continuous variables were checked for normality by using Shapiro wilk test. Independent Student $t(t)$ test (for normally distributed data) and Mann Whitney test (for normally distributed data) were used to compare means of two groups. Percent of categorical variables were compared using the Chi-square $(\chi 2)$ test. The multivariate logistic regression analysis model was done using any predictor with $\mathrm{p}<0.05$ in the univariate analysis. $\mathrm{P}<0.05$ was considered statistically significant, $\mathrm{p} \leq 0.005$ was considered highly statistically significant, and $p \geq 0.05$ was considered not statistically significant.

\section{Results}

The present study included 98 patients with a mean age of $3.27 \pm 1.53$ years. The largest percentage of the studied patients were male 
$(63.3 \%)$, half of them came from rural origin, with about $45 \%$ of them were on low social class. The baseline characteristics were reported in Table 1. Out of the 98 included children, 22 $(22.4 \%)$ were suffering from OME, and 67 (77.6\%) without OME.

There is a statistically significant difference between the studied groups regarding crowding index (odds ratio of index more than 2 per room in developing OME was 5.84), mother education (odds ratio of lower education was 3 ), and parent smoking (odds ratio for a positive history of smoking 2.68). On the other hand, no significant difference was present between both groups regarding age, gender (OR of female 1.26), residence (OR of rural 1.27), and social class (OR of low 1.03). In addition, there is a statistically significant difference between the studied participants without and with OME regarding the type of feeding (odds ratio of bottle feeding 3.69). there is also significant difference between them and history of $\mathrm{AOM}$ and snoring with (OR of AOM $=6.55$ (95\% CI; $2.27-18.92)$, (OR of snoring $=2.6$ (95\% CI; $0.987-6.85)$ respectively Table 2.
Results of univariate analysis of factors with statistical significance $<0.05$ were reviewed using multivariate backward regression analysis model. Only four factors were found significant in this analysis: crowding index $>2$ /room $(\mathrm{OR}=$ 9.36, 95\% CI: $1.782-118.633)$, parent smoking in the household $(\mathrm{OR}=3.728,95 \% \mathrm{CI}: 1.178-$ 11.8), low mother education $(\mathrm{OR}=9.021,95 \%$ CI: 1.907-9.021) and recurrent AOM $(\mathrm{OR}=7.27,95 \%$ CI: 2.197-24.071), Table 3.

There is statistically significant difference between the studied patients (with and without OME) regarding emotional functioning (57.27 \pm 17.51 versus $69.21 \pm 17.11, \mathrm{p}=0.003)$, school performance $(51.36 \pm 19.83$ versus $69.87 \pm$ $27.64, \mathrm{p}=0.002)$ and total quality of life $(47.52$ \pm 7.67 versus $54.45 \pm 9.13$, $\mathrm{p}=0.002$ ) domains. All domains were significantly lower among patients with OME, as seen in Figure 1 and Table 4. There is a statistically significant difference between the studied groups regarding parents' perceived stress (All parents of patients with OME had moderate to high stress, $\mathrm{P}<0.001$, Figure 2 and Table 5).

\section{Tables}

Table 1: Distribution of the studied patients according to demographic characteristics.

\begin{tabular}{|l|c|c|}
\hline & Mean \pm SD & Range \\
\hline Age & $3.27 \pm 1.53$ & $1-6$ \\
\hline Gender: & $\mathbf{N}(\mathbf{9 8})$ & \% \\
\hline Male & 62 & 63.3 \\
\hline Female & 36 & 36.7 \\
\hline Residence: & \multicolumn{2}{|c|}{} \\
\hline Rural & 49 & 50 \\
Urban & 49 & 50 \\
\hline Social class: & & \\
Low & 44 & 44.9 \\
Middle & 40 & 40.8 \\
High & 14 & 14.3 \\
\hline Parent smoking: & & \\
No & 62 & 63.3 \\
Yes & 36 & 36.7 \\
\hline SD; Standerd deviation & & \\
\hline
\end{tabular}


Table 2: Comparison between the studied patients with and without OME regarding demographic characteristics and tehir past history:

\begin{tabular}{|c|c|c|c|c|c|}
\hline & With OMIE & Without OME & \multirow[t]{2}{*}{$\mathbf{Z}$} & \multirow[t]{2}{*}{$\mathbf{p}$} & \multirow{2}{*}{$\begin{array}{l}\text { OR for OME } \\
(95 \% \mathrm{CI})\end{array}$} \\
\hline & Mean \pm SD & Mean \pm SD & & & \\
\hline \multirow[t]{2}{*}{ Age (years) } & $3.55 \pm 1.49$ & $3.2 \pm 1.55$ & -1 & 0.317 & \\
\hline & $\mathrm{N}=22(\%)$ & $\mathrm{N}=76(\%)$ & $\mathbf{X} 2$ & $\mathbf{P}$ & \\
\hline $\begin{array}{l}\text { Gender: } \\
\text { Male } \\
\text { Female }\end{array}$ & $\begin{array}{c}13(59.1) \\
9(40.9)\end{array}$ & $\begin{array}{l}49(64.5) \\
27(35.5)\end{array}$ & 0.213 & 0.645 & $1.26(0.48-3.32)$ \\
\hline $\begin{array}{l}\text { Residence: } \\
\text { Rural } \\
\text { Urban }\end{array}$ & $\begin{array}{l}10(45.5) \\
12(54.5)\end{array}$ & $\begin{array}{l}39(51.3) \\
37(48.7)\end{array}$ & 0.234 & 0.628 & $1.27(0.49-3.28)$ \\
\hline $\begin{array}{l}\text { Social class: } \\
\text { Low } \\
\text { Middle } \\
\text { High }\end{array}$ & $\begin{array}{l}10(45.5) \\
9(40.9) \\
3(13.6)\end{array}$ & $\begin{array}{l}34(44.7) \\
31(40.8) \\
11(14.5)\end{array}$ & 0.760 & 0.684 & $1.03(0.4-2.67)$ \\
\hline $\begin{array}{l}\text { Crowding index: } \\
\leq 2 / \text { room } \\
>2 / \text { room }\end{array}$ & $\begin{array}{c}9(40.9) \\
13(59.1)\end{array}$ & $\begin{array}{l}55(72.4) \\
21(27.6)\end{array}$ & 4.267 & $0.039 *$ & $5.84(0.91-37.49)$ \\
\hline $\begin{array}{l}\text { Mother } \\
\text { education: } \\
\text { Low } \\
\text { High }\end{array}$ & $\begin{array}{l}14(63.6) \\
8(36.4)\end{array}$ & $\begin{array}{l}28(36.8) \\
48(63.2)\end{array}$ & 5 & $0.025 *$ & $3(1.12-8.04)$ \\
\hline $\begin{array}{l}\text { Parent smoking: } \\
\text { No } \\
\text { Yes }\end{array}$ & $\begin{array}{c}8(36.4) \\
14(63.6)\end{array}$ & $\begin{array}{l}46(60.5) \\
30(39.5)\end{array}$ & 4.026 & $0.045 *$ & $2.68(1-7.17)$ \\
\hline $\begin{array}{l}\text { Type of delivery: } \\
\text { Vaginal } \\
\text { CS }\end{array}$ & $\begin{array}{c}9(40.9) \\
13(59.1)\end{array}$ & $\begin{array}{l}40(52.6) \\
36(47.4)\end{array}$ & 0.928 & 0.333 & $1.61(0.613-4.2)$ \\
\hline $\begin{array}{l}\text { Feeding: } \\
\text { Breast } \\
\text { Artificial } \\
\text { Mixed }\end{array}$ & $\begin{array}{c}3(13.6) \\
10(45.5) \\
9(40.9)\end{array}$ & $\begin{array}{l}17(22.4) \\
14(18.4) \\
45(59.2)\end{array}$ & 6.766 & $0.034 *$ & $3.69(1.33-10.24)$ \\
\hline $\begin{array}{l}\text { Pacifier use: } \\
\text { No } \\
\text { Yes }\end{array}$ & $\begin{array}{c}9(40.9) \\
13(59.1)\end{array}$ & $\begin{array}{l}39(51.3) \\
37(48.7)\end{array}$ & 0.739 & 0.39 & $1.52(0.58-3.98)$ \\
\hline $\begin{array}{l}\text { Recurrent AOM: } \\
\text { No } \\
\text { Yes }\end{array}$ & $\begin{array}{l}6(27.3) \\
16(72.7)\end{array}$ & $\begin{array}{ll}54 & (71.1) \\
22 & (28.9)\end{array}$ & 13.775 & $<0.001 * *$ & $6.55(2.27-18.92)$ \\
\hline $\begin{array}{l}\text { Snoring: } \\
\text { No } \\
\text { Yes }\end{array}$ & $\begin{array}{l}10(45.5) \\
12(54.5)\end{array}$ & $\begin{array}{ll}52 & (68.4) \\
24 & (31.6)\end{array}$ & 3.872 & 0.049* & $2.6(0.987-6.85)$ \\
\hline
\end{tabular}

Khaled A., et al.. 
Table 3: Multivariate logistic regression of variables independently predict the occurrence of OME among the studied patients:

\begin{tabular}{|c|c|c|c|c|}
\hline \multirow[t]{2}{*}{ Variables } & \multirow[t]{2}{*}{ OR } & \multicolumn{2}{|c|}{$95 \% \mathrm{CI}$} & \multirow[t]{2}{*}{$\mathbf{P}$} \\
\hline & & Lower & Upper & \\
\hline Crowding index (>2/room) & 9.36 & 1.782 & 118.633 & $0.022 *$ \\
\hline Parent smoking (yes) & 3.728 & 1.178 & 11.8 & $0.025^{*}$ \\
\hline Recurrent AOM & 7.27 & 2.197 & 24.071 & $0.001 * *$ \\
\hline Low maternal education ${ }^{¥}$ & 2.86 & 1.907 & 9.021 & $0.023 *$ \\
\hline \multicolumn{5}{|c|}{$\begin{array}{l}{ }^{*} p<0.05 \text { is statistically significant }{ }^{* *} p \leq 0.001 \text { is statistically highly significant } \\
{ }^{*} \text { Low maternal education includes illiterate, Read and write, Basic education } \\
\text { AME, Acute otitis media; OR, odds ratio; CI confidence interval. }\end{array}$} \\
\hline
\end{tabular}

Table 4: Comparison between the studied groups regarding the quality of life domains:

\begin{tabular}{|c|c|c|c|}
\hline & With OME & Without OMIE & $\mathbf{p}$ \\
\hline & Mean \pm SD & Mean \pm SD & \\
\hline Physical functioning domain & $58.81 \pm 20.29$ & $55.35 \pm 20.66$ & 0.51 \\
\hline Emotional functioning domain & $57.27 \pm 17.51$ & $69.21 \pm 17.11$ & $0.003 *$ \\
\hline Social functioning domain & $22.63 \pm 16.3$ & $23.37 \pm 23.21$ & 0.6 \\
\hline School performance domain & $51.36 \pm 19.83$ & $69.87 \pm 27.64$ & $0.002 *$ \\
\hline Total QoL domain & $47.52 \pm 7.67$ & $54.45 \pm 9.13$ & $0.002 *$ \\
\hline
\end{tabular}

Table 52: Comparison between the studied patients with and without OME regarding parents' perceived stress:

\begin{tabular}{|c|c|c|c|c|}
\hline & With OME & Without OME & \multirow[t]{2}{*}{$\mathrm{X} 2$} & \multirow[t]{2}{*}{$\mathbf{p}$} \\
\hline & $\mathbf{N}(\%)$ & $\mathbf{N}(\%)$ & & \\
\hline $\begin{array}{l}\text { Perceived stress: } \\
\text { Low } \\
\text { Moderate } \\
\text { High }\end{array}$ & $\begin{array}{l}0(0) \\
15(68.2) \\
7(31.8)\end{array}$ & $\begin{array}{l}8(10.6) \\
66(86.8) \\
2(2.6)\end{array}$ & 18.86 & $<0.001 * *$ \\
\hline
\end{tabular}




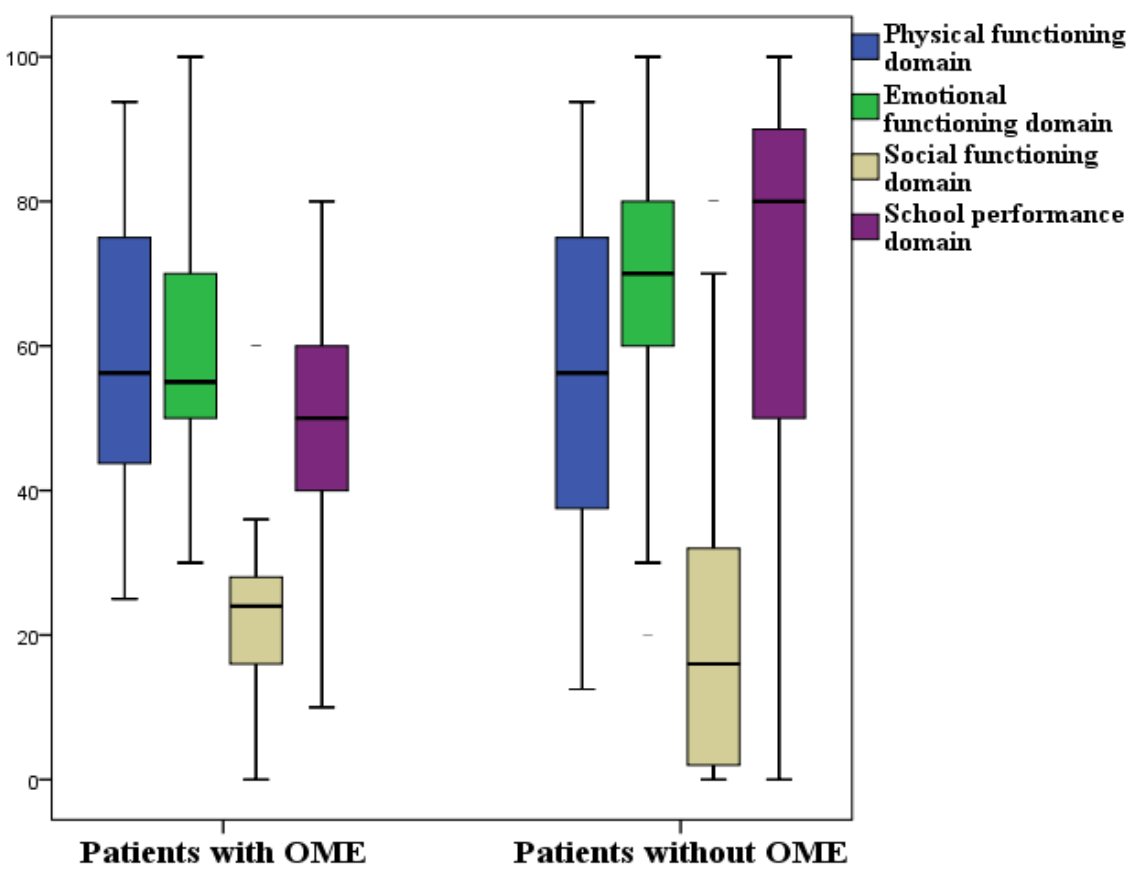

Figure 1. Boxplot graph showing the distribution of the studied groups according to QoL domains OME, otitis media with effusion

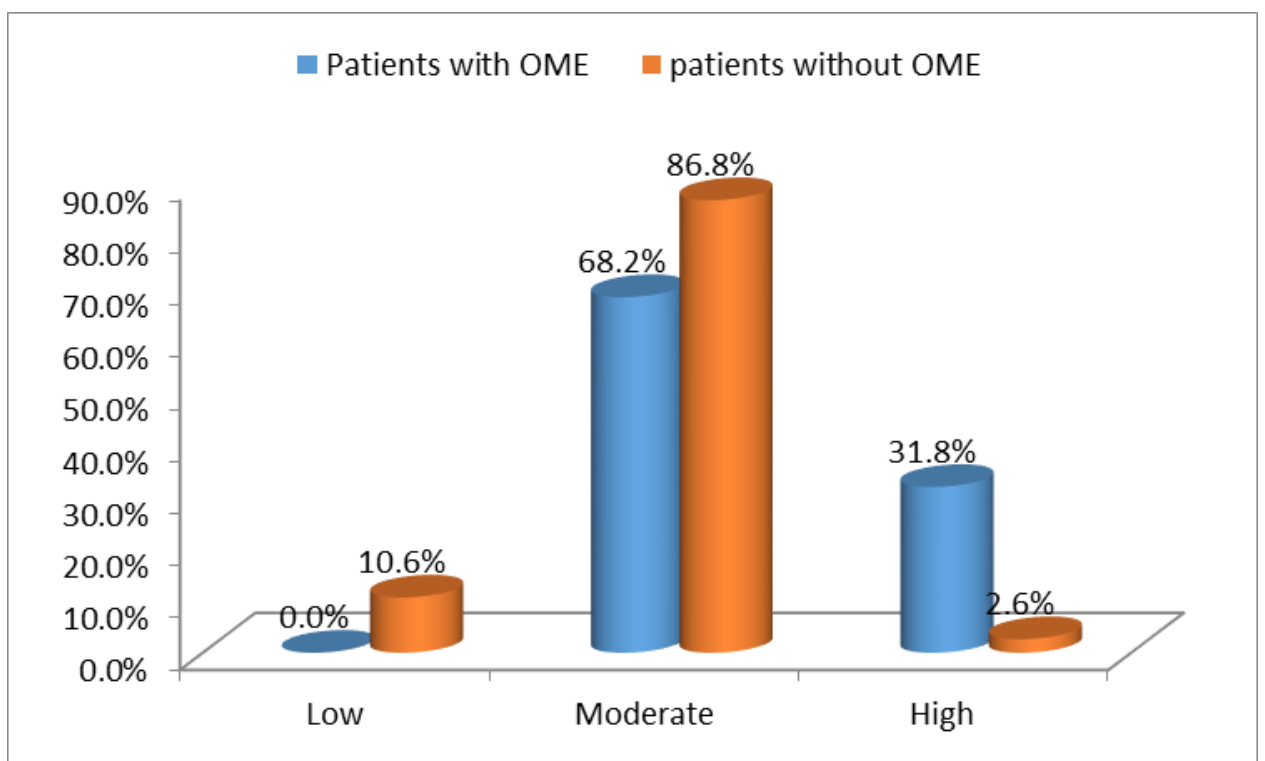

Figure 2: combined bar chart showing distribution of Parents of the studied groups according to OME, otitis media with effusion perceived stress.

\section{DISCUSSION}

In this study, the frequency of patients with OME was $22(22.4 \%)$ out of the total children that visited the otolaryngology clinic at Zagazig University. In addition, boys were more affected with OME than girls (59.1 vs. 40.9\%). This is in agreement with previous studies, who reported that boys are more likely to have OME than girls. ${ }^{10}$. This finding may be associated with a difference in geography and season of studied patients ${ }^{11}$.

The data from the world pediatric practice showed that most of the clinicians follow the clinical practice guidelines worldwide. For 
example, only $10 \%$ to $35 \%$ of pediatricians use pneumatic otoscopy for diagnosis, and 30\% obtain an age-appropriate hearing test when the OME persists. Moreover, 33\% treat OME inappropriately with antibiotics, which results in unnecessary adverse events and bacterial resistance ${ }^{11}$.

It has been reported that children with hearing problems aged 1.5 -19 years have difficulties with: attention, behavior, communication, conduct, relationships, emotions, and social behavior. It assumed that children with severe hearing problems might have poor outcomes, but it has been reported that children with mild hearing problems actually exhibit the worst psychosocial health-related quality of life ${ }^{12}$.

The mean age of the studied patients was $3.27 \pm$ 1.53. The largest percentage of the studied patients were males $(63.3 \%)$, half of them came from rural origin, and $45 \%$ of them were low social class. Most of our patients were of low socioeconomic status, as seen in many recent studies. In India, reported that only $4 \%$ of OME cases belong to the upper class and $96 \%$ belong to middle and lower classes. ${ }^{13}$

Furthermore, we found no association between sex and OME. There are some studies that discussed the higher prevalence in males, but most of the publications have not shown an effect of sex on OME ${ }^{14}$. In addition, neither male nor female gender was identified as strong predictor of OME in school children ${ }^{15}$. The largest percentage of patient's parents $(63.3 \%)$ were nonsmokers, and there was a significant difference between patients with and without OME and a significantly elevated odds ratios $(\mathrm{OR}=2.68)$ for a positive history of smoking was detected smoking. Smoking is one of the most studied risk factors of OME.

In a review study, they reported that there is insufficient data to indicate a relationship between passive smoking and middle ear disease. In literature, there are studies that deny any association between parental smoking and $\mathrm{OME}^{16}$.

However, many other studies demonstrate a clear relationship between them. It was noted that clearance of glue was statistically less frequent where the child's mother or where both parents smoked ${ }^{14}$.

The largest percentage of the studied patients had a history of mixed breast and bottle feeding $55.1 \%$ and pacifier use $51 \%$. Also, there was a significant difference between the studied groups (with and without OME) regarding the type of feeding $(\mathrm{OR}=3.69, \mathrm{P}<0.05)$ but no significant difference regarding type of delivery and pacifier use. This contradicted the finding of previous studies which stated that the type of infant feeding during the first two years of life did not have a significant effect on the prevalence of OME. Besides, another study found that the occurrence of otitis media was associated with pacifier use considering it as one of the modifiable risk factors for otitis media ${ }^{17}$.

Moreover, there was a statistically significant difference between the studied groups regarding crowding index $(\mathrm{OR}=5.84,95 \% \mathrm{CI}$ : $0.91-37.49)$. On the other hand, no significant difference was present between both groups regarding age, gender, residence, and social class. Our results are similar to those reported by previous studies. They found that the probability of disease increases with each additional brother or sister ${ }^{15}$.

There is a positive correlation between socioeconomic status and OME. Children of lower socioeconomic status are more susceptible to OME as reported by earlier studies ${ }^{18}$. In a screening study comparing families with low and high socioeconomic status in Brazil, the incidence of OME was found to be higher among children of families with low socioeconomic status and resolution of the condition was observed to be reduced ${ }^{19}$. Another study reported that the higher the socioeconomic status, higher prevalence the otitis media. They found that about $43 \%$ of patients with OME belong to the upper lower class ${ }^{20}$. However, in our study, no significant difference was present between both groups regarding social level.

In our study, low mother education was found to be a risk factor for OME. In the multivariate regression model, low mother education was 
found to be an independent predictor of OME $(P<0.05 ; \quad \mathrm{OR}=3, \quad 95 \%$ CI: 1.12-8.04). Similarly, ${ }^{21}$, reported a higher prevalence of OME in families with less parental education. Also, other studies found that lower levels of maternal education were associated with poorer knowledge regarding otitis media ${ }^{15}$.

The largest percentage of the studied patients with OME had history of recurrent AOM $(72.7 \%)$ or snoring $(54.5 \%)$. In univariate analysis, children with recurrent AOM were more likely to have recurrently OME [OR=6.55; 95\% CI 2.27 - 18.92)] (table 2) in contradict with a previous study ${ }^{22}$ Reported that some of the children continue to have middle ear problem secondary to Eustachian tube dysfunction and large adenoid, particularly in first or second grade. Also, in the multivariate regression model, we found recurrent AOM to be a strong predictor of OME. Previous studies similarly found that children with a history of recurrent $\mathrm{AOM}$ are more likely to have OME 23,24

Other study had investigated the psychosocial health-related quality of life outcomes of children with OM and predominantly report lower psychosocial issues. It has been reported that children with hearing problems are showed to be 3.6 times more likely to have psychological difficulties and three times more likely to have moderate to severe mental health problems than hearing children ${ }^{25}$.

Our findings showed a statistically significant difference between the studied groups regarding parents' perceived stress and all parents of patients with OME had moderate to high stress.

This might be because parents initially believe that otitis media is a short-term illness, and when the disease is prolonged or reoccurs, they become anxious and weary in coping with managing the disease and treatment ${ }^{26}$.

On the other hand, this study has some limitations. Due to the nature of the study as a cross-sectional study, the relation between risk factors and outcome cannot be proved. The sample size was relatively small. No audiological tests were done. Only tympanometry was used.

We concluded that the frequency of OME among children attending the otolaryngology clinic at Zagazig University was about $22 \%$. Low mother education was found to be a risk factor for OME. Children with recurrent AOM were more likely to have recurrent OME. We also found that parent smoking in the household and recurrent AOM were strong predictors of the occurrence of OME among the studied children. Interestingly, children with OME reported significantly poorer quality of life than their peers without OME regarding emotional functioning, school performance, and total QoL. These findings demonstrate that a true difference in QoL likely exists between children with and without OME. Parents of children with OME had higher perceived stress making OME a serious problem threatening the whole family.

Large scale prospective study should be done to prove relation between suggested risk factors and development of OME. Parents education programs are recommended to prevent and early diagnose OME. Also, surveillance of OME should be routine procedure especially in this golden age (preschool children). Formal evaluation of hearing with correlating its degree with QoL is strongly recommended.

Funding: None to declare

Conflict of Interest: None to declare

\section{REFERENCES}

1. Lok, W., Anteunis, L. J. C., Chenault, M. N., Meesters, C. \& Haggard, M. P. Screening for hearing loss versus parental concern regarding hearing problems: Subsequent referral and treatment for otitis media in the Netherlands. Scand. J. Prim. Health Care 30, 163-168 (2012).

2. Kaur, R., Morris, M. \& Pichichero, M. E. Epidemiology of Acute Otitis Media in the Postpneumococcal Conjugate Vaccine Era. Pediatrics 140, (2017).

3. Williamson, I. Otitis media with effusion in children. Clin. Evid. (Online). 2007, (2007).

4. Hall, A. J., Maw, R., Midgley, E., Golding, J. \& Steer, C. Glue Ear, Hearing Loss and IQ: An Association Moderated by the Child's Home Environment. PLoS One 9, e87021 (2014).

5. Rettig, E. \& Tunkel, D. E. Contemporary 
Concepts in Management of Acute Otitis Media in Children. Otolaryngol. Clin. North Am. 47, 651672 (2014).

6. Bellussi, L.. Quality of life and psycho-social development in children with otitis media with effusion. Acta Otorhinolaryngol. Ital. 25, 359-64 (2005).

7. Jung, T. T. K.. Panel 8. Otolaryngol. Neck Surg. 148, E122-E143 (2013).

8. Varni, J. W., Burwinkle, T. M. \& Lane, M. M. Health-related quality of life measurement in pediatric clinical practice: An appraisal and precept for future research and application. Health Qual. Life Outcomes 3, 34 (2005).

9. Cohen, S. Perceived Stress Scale. (1994).

10. Mohammed, M., Elsherief, W., Osman, M. \& Abdelmaksoud, A. Role of medical management in otitis media with effusion Journal of Current Medical Research and Practice. J. Curr. Med. Res. Pract. 1, 24 (2016).

11. Payne, S. C. Clinical Practice Guideline: Otitis Media with Effusion (Update). Otolaryngol. Neck Surg. 154, S1-S41 (2016).

12. Hogan, A., Phillips, R. L., Howard, D. \& Yiengprugsawan, V. Psychosocial outcomes of children with ear infections and hearing problems: a longitudinal study. BMC Pediatr. 14, 65 (2014).

13. Park, K. Park's textbook of preventive and social medicine. (M/s Banarsidas Bhanot, 2007).

14. Erdivanli, O. C., Coskun, Z. O., Kazikdas, K. C. \& Demirci, M. Prevalence of Otitis Media with Effusion among Primary School Children in Eastern Black Sea, in Turkey and the Effect of Smoking in the Development of Otitis Media with Effusion. Indian J. Otolaryngol. Head Neck Surg. 64, 17-21 (2012).

15. Humaid, A.-H. I.. Prevalence and risk factors of Otitis Media with effusion in school children in Qassim Region of Saudi Arabia. Int. J. Health Sci. (Qassim). 8, 325-34 (2014).

16. Tong, M. C. F. Risk factors for otitis media with effusion in Chinese schoolchildren: A nested casecontrol study and review of the literature. Int. J. Pediatr. Otorhinolaryngol. 70, 213-219 (2006).
17. Rovers, M. M. Is pacifier use a risk factor for acute otitis media? A dynamic cohort study. Fam. Pract. 25, 233-236 (2008).

18. Chadha, S. K., Agarwal, A. K., Gulati, A. \& Garg, A. A comparative evaluation of ear diseases in children of higher versus lower socioeconomic status. J. Laryngol. Otol. 120, (2006).

19. Castagno, L. A. \& Lavinsky, L. Otitis media in children: seasonal changes and socioeconomic level. Int. J. Pediatr. Otorhinolaryngol. 62, 129-34 (2002).

20. Siddartha, Bhat, V., Bhandary, S. K., Shenoy, V. \& Rashmi. Otitis Media with Effusion in Relation to Socio Economic Status: A Community Based Study. Indian J. Otolaryngol. Head Neck Surg. 64, 56-58 (2012)

21. Gultekin, E., Develioğlu, Ö. N., Yener, M., Ozdemir, I. \& Külekçi, M. Prevalence and risk factors for persistent otitis media with effusion in primary school children in Istanbul, Turkey. Auris Nasus Larynx 37, 145-149 (2010).

22. Kırıs, M.. Prevalence and risk factors of otitis media with effusion in school children in Eastern Anatolia. Int. J. Pediatr. Otorhinolaryngol. 76, 1030-1035 (2012).

23. Alho, O. P., Oja, H., Koivu, M. \& Sorri, M. Risk factors for chronic otitis media with effusion in infancy. Each acute otitis media episode induces a high but transient risk. Arch. Otolaryngol. Head. Neck Surg. 121, 839-43 (1995).

24. Martines, F., Bentivegna, D., Maira, E., Sciacca, V. \& Martines, E. Risk factors for otitis media with effusion: Case-control study in Sicilian schoolchildren. Int. J. Pediatr. Otorhinolaryngol. 75, 754-759 (2011).

25. Leigh, G. Factors Affecting Psychosocial and Motor Development in 3-Year-Old Children Who Are Deaf or Hard of Hearing. J. Deaf Stud. Deaf Educ. 20, 331-42 (2015).

26. Hansen, M. P., Howlett, J., Del Mar, C. \& Hoffmann, T. C. Parents' beliefs and knowledge about the management of acute otitis media: a qualitative study. BMC Fam. Pract. 16, 82 (2015).

\section{HOW TO CITE}

Mohammed, K., AbdAllah, A., mohammed, M. Frequency Of Otitis Media with Effusion Among Preschool Children and Its Effect On Both Children And Their Parents: A Cross-sectional Study. Zagazig University Medical Journal, 2021; 2(209-218): -. doi: 10.21608/zumj.2019.13437.1246 